\title{
Contribuições do Parque Zoológico de Goiânia para a alfabetização científica: um relato de experiência
}

\author{
Contributions of the Parque Zoológico de Goiânia to scientific literacy: an experience report \\ Contribuciones del Parque Zoológico de Goiânia a la alfabetización científica: un informe de
} experiencia

Elenice Barbosa Abrão

ORCID: https://orcid.org/0000-0001-6364-5621

Universidade Estadual de Goiás, Brasil E-mail: eleniceabraobiol@gmail.com

Cleide Sandra Tavares Araújo

ORCID: https://orcid.org/0000-0001-5080-6465 Universidade Estadual de Goiás, Brasil E-mail: cleide.araujo@ueg.br

Solange Xavier dos Santos

ORCID: https://orcid.org/0000-0002-3397-0885 Universidade Estadual de Goiás, Brasil E-mail: solangexavier@ueg.br

\begin{abstract}
Resumo
Este trabalho teve por objetivo apresentar as contribuições do Parque Zoológico de Goiânia (PZG) para o processo de alfabetização científica. É relatada uma experiência realizada com alunos do $5^{\circ}$ ano do Ensino Fundamental de uma escola conveniada com a rede estadual de educação de Goiás. A atividade foi conduzida em cinco etapas: uma roda de conversa (para as apresentações e interação entre a pesquisadora, a pesquisa e os alunos), a sondagem dos conhecimentos prévios dos alunos sobre a Fauna e a Flora, especialmente a do Cerrado (através de um questionário e de desenhos), uma visita monitorada ao PZG, a verificação do conhecimento dos alunos pós-visita (através de um questionário e desenhos) e a socialização desse conhecimento (através da produção e exposição de desenhos) para a comunidade escolar. A análise dos dados obtidos mostra que, após a visita, os alunos demonstraram aumento significativo no conhecimento sobre o tema em questão. Os alunos destacaram em seus desenhos e respostas aos questionários, espécies e características de animais e de plantas que fazem parte da Fauna e Flora do Cerrado, antes desconhecidos, o que demonstra que o PZG constitui um espaço não formal com grandes possibilidades para desenvolver a aprendizagem e que contribui para o processo de alfabetização científica dos alunos que o visitam.
\end{abstract}

Palavras-chave: Ciências; Biodiversidade; Espaços não formais de aprendizagem.

\begin{abstract}
This paper aimed to present the contributions of the Zoological Park of Goiânia (PZG) to the scientific literacy process. An experience carried out with 5th grade students from a school associated with the state education system of Goiás is reported. The activity was conducted in five stages: a conversation circle (for introductions and interaction between the researcher, the research and the students), a survey of the students' previous knowledge about Fauna and Flora, especially that of the Cerrado (through a questionnaire and drawings), a monitored visit to the PZG, the verification of the students' post-visit knowledge (through a questionnaire and drawings), and the socialization of this knowledge (through the production and exhibition of drawings) to the school community. The analysis of the data obtained shows that, after the visit, the students demonstrated a significant increase in their knowledge about the theme in question. The students highlighted in their drawings and answers to the questionnaires, animals and plant species that are part of the Fauna and Flora of the Cerrado, previously unknown, as well as some characteristics, which shows that the PZG is a non-formal space with great possibilities for developing learning and that contributes to the process of scientific literacy of the students who visit it.
\end{abstract}

Keywords: Sciences; Biodiversity; Non-formal learning spaces.

\section{Resumen}

Este trabajo tiene como objetivo presentar las contribuciones del Parque Zoológico de Goiânia (PZG) para el proceso de alfabetización científica. Se relata una experiencia realizada con alumnos de $5^{\circ}$ año de primaria en una escuela asociada a la red estatal de educación de Goiás. La actividad se llevó a cabo en cinco etapas: una ronda de conversación (para las presentaciones y la interacción entre el investigador, la investigación y los estudiantes), el 
sondeo de los conocimientos previos de los estudiantes sobre la Fauna y la Flora, especialmente la del Cerrado (a través de un cuestionario y dibujos), una visita monitoreada al PZG, la verificación de los conocimientos de los estudiantes después de la visita (a través de un cuestionario y dibujos), y la socialización de estos conocimientos (a través de la producción y exposición de dibujos) a la comunidad escolar. El análisis de los datos obtenidos muestra que, tras la visita, los alumnos demostraron un aumento significativo de sus conocimientos sobre el tema en cuestión. Los alumnos destacaron en sus dibujos y en las respuestas a los cuestionarios, animales y especies vegetales que forman parte de la Fauna y Flora del Cerrado, que hasta ahora eran desconocidos, así como algunas características, lo que demuestra que el PZG es un espacio no formal con grandes posibilidades para desarrollar el aprendizaje y que contribuye al proceso de alfabetización científica de los alumnos que lo visitan.

Palabras clave: Ciencias; La biodiversidad; Espacios de aprendizaje no formal.

\section{Introdução}

O avanço da Ciência e as novas tecnologias têm contribuído para o rápido processo de transformação da nossa sociedade. $\mathrm{O}$ incremento dos modos de produção, a capacidade de comunicação e a grande oferta de serviços são indícios de que vivenciamos uma revolução tecnológica. Entretanto, o acesso às novas tecnologias não significa que haja aquisição de conhecimento científico. Sem sua devida compreensão, as pessoas tornam-se simplesmente usuárias da tecnologia e, portanto, incapazes de solucionar problemas e de contribuir para o processo de transformação da sociedade (Araújo, Chessini \& Filho, 2014).

Nesse contexto, Laugksch (2000) esclarece que a alfabetização científica tornou-se um objetivo contemporâneo, pois as pessoas, de um modo geral, devem apropriar-se de conhecimentos científicos para serem capazes de desenvolver o senso crítico e fazer escolhas conscientes. Para o autor, o termo Alfabetização Científica (AC) é controverso, devido às concepções e às interpretações dos diferentes grupos de interesses, cada um voltado para um público específico. O autor ainda esclarece que há uma diversidade de conceitos de AC. Entretanto, para Chassot (2003), o conceito pode ser entendido como a capacidade de saber ler, interpretar a natureza, descrever este conhecimento através de uma linguagem científica, compreender a nós mesmos, o mundo e, se possível, transformá-lo para melhor.

Para Sasseron (2015), a AC é norteada por três eixos: o primeiro tem como finalidade compreender termos e conceitos científicos; o segundo permite o entendimento da natureza da ciência e dos aspectos que influenciam sua prática e, o terceiro eixo, tem como objetivo a compreensão das relações entre ciência, tecnologia, sociedade e ambiente, o que permite uma visão mais ampla da ciência e presume relações que influenciam a produção de conhecimento e a compreensão da diversidade existente na interação entre homem e natureza.

Nesse sentido, para Sasseron e Carvalho (2008), é fundamental que os alunos desenvolvam habilidades que estejam próximas do trabalho desenvolvido pelos cientistas. Essas autoras sugeriram indicadores de AC para serem trabalhados durante a execução das aulas, os quais podem evidenciar indícios do processo de AC dos alunos. Tais indicadores relacionamse especificamente com algumas competências oriundas das Ciências e do processo de construção científica dos alunos.

Para ser cientificamente culto, não basta a aquisição de conhecimentos e competências tradicionalmente apresentadas de jure nos currículos de Ciências, desde cedo orientados, de fato, para quem pretende seguir futuros estudos de Ciências (ainda que a maioria dos alunos não o faça). Ser cientificamente culto implica também atitudes, valores e novas competências (em particular, abertura à mudança, ética de responsabilidade, aprender a aprender...) capazes de ajudar a formular e debater responsavelmente um ponto de vista pessoal sobre problemáticas de índole científico/tecnológica, juízos mais informados sobre o mérito de determinadas matérias e situações com implicações pessoais e/ou sociais, participação no processo democrático de tomada de decisões, uma melhor compreensão de como idéias da Ciência/Tecnologia são usadas em situações sociais, econômicas, ambientais e tecnológicas específicas (Cachapuz, 2004, p. 367).

Cachapuz (2004) esclarece que o ensino de Ciências deve ser contextualizado, abranger as dimennsões da Ciência no sentido de fazer o aluno compreender para que serve determinado conhecimento na vida prática; promover a autoconfiança do 
aluno através do saber fazer a partir do conhecimento adquirido (dimensão pessoal) e ao mesmo tempo contribuir para que o aluno possa utilizar o conhecimento adquirido. No contexto da dimensão social, o aluno deve ser capaz de resolver situações problema que afetam a vida social.

Além de estar inserida no contexto escolar, a AC também pode ter como cenário os espaços não formais de aprendizagem. Jacobucci (2008) esclarece que o termo espaço não formal de aprendizagem tem sido utilizado de forma ampla para explicar os espaços diferentes da escola, em que é possível desenvolver atividades educativas. Nesse sentido, na tentativa de tornar o ensino de Ciências mais atrativo, as escolas têm utilizado esses espaços como estratégias diferenciadas que oportunizam a interação e a aprendizagem (Queiroz, R., Teixeira, Veloso, Terán \& Queiroz, A., 2011).

As experiências e emoções vivenciadas em espaços não formais permitem uma aprendizagem cognitiva siginificativa para os estudantes (Fernandes, 2007). Segundo Sousa e Campos (2020), as atividades de campo colaboram para que os alunos façam uma interpretação sistemática e crítica do meio ambiente, bem como incentivam questionamentos oriundos de problemáticas da realidade em questão. Nesse sentido, os zoológicos são espaços institucionalizados que contribuem para o processo de construção do conhecimento, uma vez que propiciam a divulgação de conteúdos e a oportunidade de conhecer diversas espécies da Fauna, suas características, comportamentos e hábitos alimentares (Queiroz et al., 2011). Nesses locais os estudantes utilizam todos os sentidos, além do visual, realizam observações diretas que permitem a compreensão da realidade por meio da mediação e ampliação do conhecimento, interação entre professores e alunos, bem como entre as experiências vivenciadas no ambiente (Lorenzetti \& Delizoicov, 2001).

Dentro deste contexto, recorremos ao pensamento sociointeracionista, da teoria histórico cultural de Vygotsky, para entender como acontece a interação e mediação no processo de aprendizagem para a AC nesse ambiente. Vygotsky considera a dimensão social, os instrumentos e símbolos os responsáveis pela mediação nas relações dos indivíduos com o mundo. Para Vygotsky, o desenvolvimento do ser humano depende do aprendizado; assim, ele identificou dois níveis de desenvolvimento: o real ou efetivo, e o potencial. Desta forma, a Zona de Desenvolvimento Proximal (ZDP), que será discutida mais adiante, está relacionada com a distância entre esses dois níveis e define as funções que ainda estão em processo de amadurecimento (Molon, 2019).

Considerando os conceitos sobre AC, espaços não formais e a teoria sócio-histórico-cultural de Vygotsky, este trabalho teve como objetivo conduzir e relatar uma experiência com alunos do ensino fundamental no Parque Zoológico de Goiânia (PZG) para verificar indícios do processo de AC nesse espaço.

\section{Metodologia}

\section{A pesquisa}

Os participantes da pesquisa foram estudantes de duas turmas do $5^{\circ}$ ano do Ensino Fundamental (EF) de uma escola filantrópica conveniada da rede estadual de ensino da cidade de Goiânia, seus dois respectivos professores regentes, e três educadores ambientais do PZG. A primeira turma é do período matutino, com 18 estudantes, a outra do vespertino, com 12 estudantes. Parte da pesquisa foi realizada no Parque Zoológico de Goiânia, que possui uma área verde, três nascentes e vegetação com espécies do Cerrado. Possui um museu de Zoologia com animais taxidermizados, e um plantel de mamíferos, répteis e aves da fauna local e internacional.

A pesquisa foi realizada através da observação não participante, conforme Marconi e Lakatos (2011). Os dados foram coletados a partir da aplicação de questionários e da produção de desenhos pelos participantes, antes e após a visita, cuja análise seguiu os preceitos da teoria sócio histórica de Vygotsky, visando compreender a Zona de Desenvolvimento Proximal para o processo de alfabetização científica dos alunos. Considerando-se que para Vygotsky através do conhecimento prévio é possível compreender o conhecimento real ou espontâneo dos estudantes (Rego, 2014), o questionário e desenho pré-visita 
objetivaram sondar os conhecimentos prévios dos estudantes. Por sua vez, o questionário e desenho pós-visita tiveram por finalidade verificar o conhecimento adquirido ou aproveitamento dos estudantes, fase que Vygotsky denominou de conhecimento potencial; e, assim compreender se a visita ao PZG contribuiu de forma significativa para o processo de alfabetização científica.

O projeto foi aprovado pelo Comitê de Ética em Pesquisa (CEP) da Universidade Estadual de Goiás, sob o parecer 4057188. Foram providenciadas as assinaturas dos Termos de Consentimento Livre e Esclarecido (TCLE) assinados por professores e educadores ambientais e Termos de Assentimento Livre esclarecido (TALE), assinados pelos responsáveis dos estudantes menores de idade. A pesquisa foi executada em cinco etapas, com intervalo de sete dias entre cada etapa, as quais são descritas a seguir

\section{Roda de conversa}

Considerando as afirmações de Moura e Lima (2014) de que a roda de conversa permite o diálogo, a interação e a aproximação dos envolvidos, optamos por utilizar esse instrumento com o propósito de conhecer a turma, promover a interação entre estudantes, professores, pesquisadora e apresentar as atividades a serem desenvolvidas durante as etapas da pesquisa.

Foi solicitado aos estudantes que organizassem as carteiras em círculo, de modo a propiciar maior interação e podermos olhar uns para os outros. Com a concordância de todos, ficou combinado que todas as atividades realizadas na sala de aula referentes ao projeto seriam conduzidas com as carteiras em semicírculo.

Após as apresentações de todos, foi explicado aos alunos o que é uma pesquisa de mestrado e o quanto a participação de cada um era importante para a pesquisa. Os estudantes foram questionados se já conheciam o zoológico, o que pensavam sobre animais em cativeiro e sobre o conceito de Fauna e Flora. As respostas obtidas foram anotadas pela professora. Em seguida, foram expostas as etapas do trabalho que seriam desenvolvidas e o passo a passo de como seriam realizadas. À medida em que a conversa fluía, os estudantes faziam questionamentos e as dúvidas eram esclarecidas.

\section{Sondagem dos conhecimentos prévios}

Para Ausubel, Novak e Hanesian (1980) os conhecimentos prévios dos alunos influenciam significativamente o processo de aprendizagem. Vygotsky (2003) corrobora com esta ideia, pois também considera relevante os conhecimentos prévios ou espontâneos para a construção do conhecimento científico. Assim, levando em conta as considerações dos autores citados, foi realizada uma sondagem dos conhecimentos prévios dos estudantes sobre o Cerrado, sua Fauna e sua Flora.

No dia programado, quando a pesquisadora chegou na sala, os alunos se encontravam organizados em semicírculo. Ela informou aos estudantes sobre as atividades do dia, incluindo uma breve explicação sobre o que são conhecimentos prévios e sua importância no processo de ensino aprendizagem.

Então, foram aplicadas duas atividades. Na primeira, foram fornecidos aos estudantes uma folha de papel A4 em branco e lápis de cor, e solicitado que cada um produzisse um desenho sobre o tema Fauna e Flora do Cerrado. Na segunda atividade, eles receberam um questionário semiestruturado, denominado pré-visita, composto de dez questões abertas e fechadas, sobre o mesmo tema (Figura 1A e 1B). Para Rocha (2020), tanto a escrita quanto o desenho são atividades que expressam os conhecimentos dos alunos e permitem que o professor compreenda avanços e dificuldades de aprendizagem. 
Figura 1 - Investigando os conhecimentos prévios dos estudantes.

A) Através do questionário pré-visita.

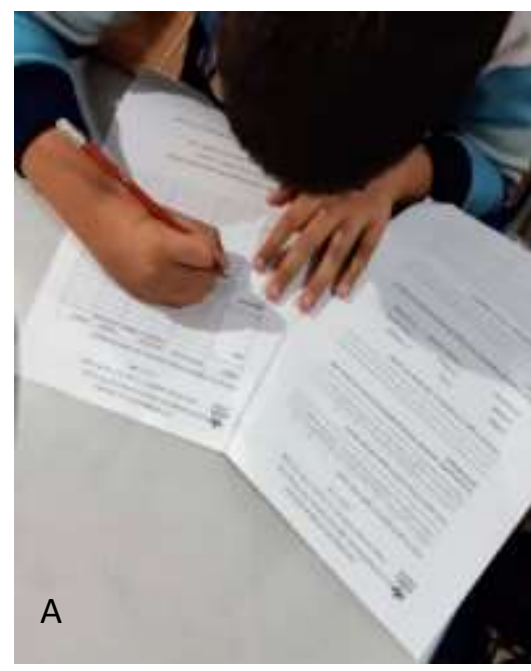

Fonte: Autores (2019)
B) Através de desenhos pré-visita.

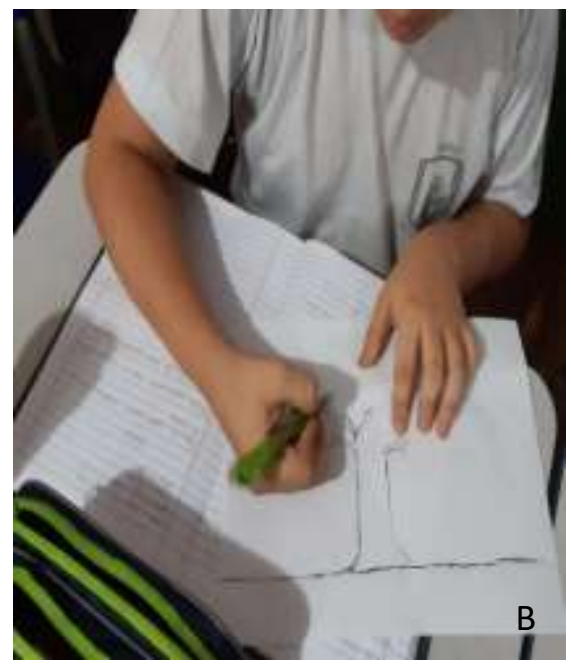

Fonte: Autores (2019)

\section{Visita ao Parque Zoológico de Goiânia}

Os alunos foram antecipadamente orientados que só poderiam participar da visita ao PZG aqueles que devolvessem o TALE devidamente assinado pelos pais, autorizando a participação dos estudantes na pesquisa. Foram informados ainda que deveriam estar uniformizados, usando bonés, tênis ou sapatos fechados confortáveis, além de levar água e lanche. As turmas foram encaminhadas ao PZG, cada uma em seu respectivo turno, por uma empresa de transporte turístico providenciado pela pesquisadora, na companhia da professora e da coordenadora pedagógica. Ao chegar ao PZG, os estudantes foram recepcionados por uma educadora ambiental e encaminhados para o Núcleo de Educação Ambiental, local em que as palestras com os visitantes são realizadas. O TCLE foi encaminhado aos professores e educadores ambientais do PZG.

Nesse ambiente os alunos foram acomodados para participar de uma palestra ministrada por uma das educadoras ambientais do PZG sobre o tema Fauna e Flora do Cerrado, a importância do PZG, a origem dos animais, seu plantel, bem como sobre as atividades que seriam desenvolvidas durante a visita, e ainda sobre as regras de conduta durante a permanência no PZG (Figura 2). 
Figura 2 - Estudantes visitantes do Parque Zoológico de Goiânia assistindo à palestra sobre o tema Cerrado.

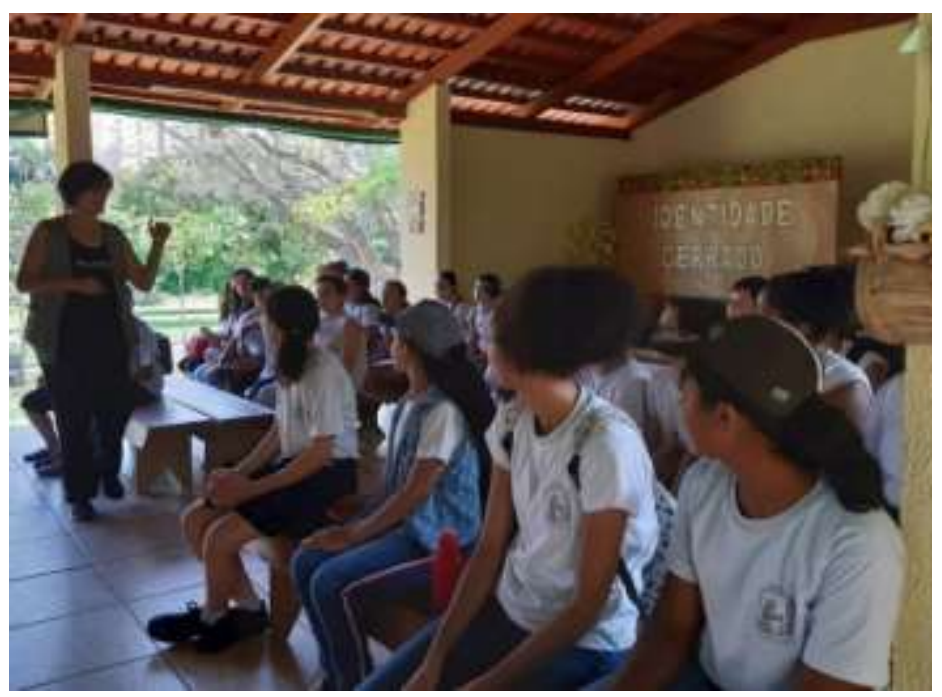

Fonte: Autores (2019).

Posteriormente, os estudantes foram conduzidos ao museu de zoologia, onde estão expostos insetos, aves, répteis e mamíferos da Fauna brasileira, inclusive do Cerrado, e também da Fauna exótica. Em seguida, os alunos foram conduzidos para a trilha pedagógica monitorada, que consistiu em percorrer todos os recintos do parque, acompanhados de um educador ambiental, com pequenas paradas em frente aos recintos dos animais, seguindo o trajeto de acordo com o planejado.

Ao longo do percurso, o educador falou (Figura 3) sobre as características dos animais, habitat, comportamento, hábitos alimentares, sobretudo enfatizando os animais da Fauna do Cerrado e, à medida que os estudantes faziam questionamentos o educador respondia. Durante o trajeto, os estudantes foram estimulados a perceber os ambientes, inclusive as espécies de árvores do Cerrado encontradas, como: cajuzinho-do-Cerrado, guariroba, ipê-amarelo, angico-do-Cerrado, pauterra, sucupira-preta, dentre outras, além de observar os animais de vida livre.

Figura 3 - Visita dos estudantes do $5^{\circ}$ ano ao recinto dos mamíferos.

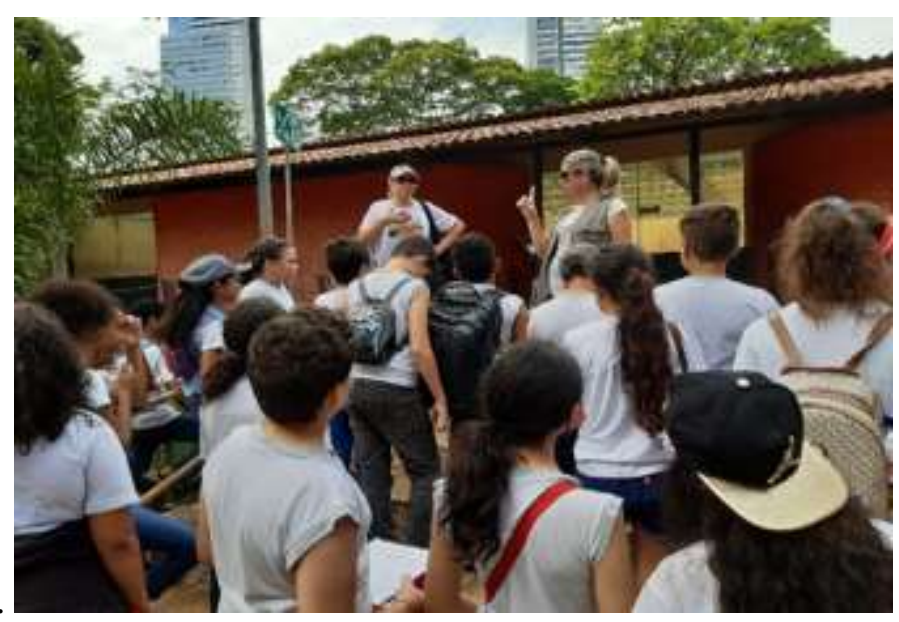

Fonte: Autores (2019).

Ao final da trilha pedagógica, os alunos participaram de uma atividade de plantio de árvores do Cerrado (Ipê-rosa), integrando uma ação planejada pelos educadores ambientais para recuperação da nascente do PZG. A visita foi encerrada e os alunos retornaram para a escola. Após o encerramento das atividades na trilha, os educadores ambientais foram entrevistados 
pela pesquisadora, mediante o direcionamento de um questionário semiestruturado, com a finalidade de investigar sua opinião sobre a atividade realizada, integração do professor e interesse dos estudantes.

\section{Verificação dos conhecimentos dos alunos após a visita}

Com o objetivo de verificar a aprendizagem dos estudantes com a visita ao PZG, foi realizado um novo processo de verificação dos conhecimentos dos estudantes, cerca de sete dias decorridos da visita. Da mesma forma que descrito anteriormente, foi solicitado aos estudantes que fizessem um desenho representativo da Fauna e Flora do Cerrado. Além disso, foi aplicado um novo questionário versando sobre os temas abordados durante a visita, o que incluiu algumas questões do primeiro questionário e outras adicionais.

Ao final da última atividade, foi realizada uma entrevista com as professoras com a finalidade de obter informações sobre suas percepções acerca das atividades desenvolvidas e da aprendizagem dos alunos.

\section{Socialização do conhecimento obtido: exposição dos desenhos produzidos pelos alunos}

Aproveitando-se de um evento previsto no calendário escolar, envolvendo apresentações bimestrais de trabalhos dos alunos em todas as disciplinas, os desenhos produzidos durante o presente projeto foram, então, apresentados em uma exposição de cerca de uma hora de duração para toda a comunidade escolar.

Durante a exposição dos desenhos, foi proposto que quatro alunos se candidatassem para apresentar os desenhos e falassem sobre a experiência realizada no PZG. Deste modo, foi possível socializar e divulgar o conhecimento adquirido com a comunidade escolar.

\section{Análise dos dados}

Os questionários pré e pós-visita foram analisados considerando as respostas dadas às questões antes e após a visita; foram também comparadas as respostas das questões que se repetem nos dois questionários.

A análise dos desenhos considerou a teoria Sócio Histórico Cultural de Vygotsky, que compreende o desenho de acordo com a realidade em que a criança está inserida, o seu processo de interação e mediação com o outro e o meio (Vigotsky, 1991). Os dados coletados em ambos os casos foram categorizados, considerando a frequência com que os elementos da Fauna e Flora aparecem tendo por base a análise de conteúdo proposta porBardin (1977), e organizados em tabelas pré e pós-visita.

Assim, a finalidade dos dados levantados pré-visita foi verificar os conhecimentos prévios dos alunos; e no pós-visita se apareceram elementos novos referentes à Fauna e à Flora do Cerrado, se houve ampliação do conhecimento.

\section{Resultados e Discussão}

A roda de conversa foi um momento informal relevante para interagir e conhecer, através do diálogo, um pouco da realidade dos estudantes. Desse modo, foi possível verificar que, dentre os 18 alunos da turma A, apenas um conhecia o PZG e dos 12 da turma B, somente dois tinham visitado o zoológico. Isso demonstra a importância das escolas, sempre que possível, planejarem e oportunizarem aos alunos atividades voltadas para visitas em espaços não formais de aprendizagem.

Ao considerar o comportamento dos estudantes durante a visita, pode-se perceber que este foi um momento agradável para ambas as turmas. Os alunos permaneceram atentos, entusiasmados e empolgados o tempo todo. As duas turmas demonstraram grande interesse pelos animais taxidermizados do Museu; os da turma A reclamaram do pouco tempo para apreciar todos os animais. Ambas as turmas ouviram e participaram com atenção da palestra, que oportunizou o conhecimento tanto da Fauna quanto da Flora do PZG. Os estudantes fizeram muitos questionamentos sobre os animais durante a trilha pedagógica e pareciam encantados com os animais e as espécies de árvores representativas da Flora do Cerrado evidenciadas . 
Ao longo do caminho fizeram leitura das placas e anotações em seus cadernos sobre os aspectos observados. Quando chegamos aos recintos dos grandes mamíferos, um dos alunos da turma B estava chorando, ao ser questionado sobre o motivo, ele respondeu: "é muito triste ver animais presos, andando de um lado para o outro sem espaço". Foi emocionante perceber que, com lágrimas, ele expressava o sentimento de compaixão pelos animais. Como encerramento das atividades ao PZG, os educadores ambientais enfatizaram a importância da arborização do Parque para proteção das nascentes do local e os alunos foram convidados para o plantio coletivo de uma muda de Ipê, o que representou um momento significativo para ambas as turmas, pois foi bastante enfatizado, posteriormente, pelos alunos. Trabalho semelhante foi relatado por Vieira, Bianconi e Dias (2005), no Jardim Zoológico do Rio de Janeiro, os autores descrevem a relevância desses espaços não formais para a interação dos alunos com o ambiente e aprendizagem de Ciências

Ao analisar os desenhos pré-visita, foi possível verificar que na turma A aparecem poucas informações que caracterizam a Fauna e Flora do Cerrado. Dos 18 desenhos analisados, dez não apresentam animais, nos oito restantes aparecem cobra, lobo-guará, tamanduá e jacaré. Em relação à Flora seis alunos não incluíram nenhum elemento representativo e os outros 12 destacaram com maior frequência características como: árvores com troncos retorcidos e cascas grossas. $\mathrm{Na}$ turma B também apareceram poucos elementos da Fauna e Flora do Cerrado. O animal que apareceu com mais frequência foi a onça-pintada; e os elementos característicos da Flora mais evidenciados foram troncos retorcidos e vegetação rasteira.

Avaliando os desenhos pós-visita percebe-se que os alunos de ambas as turmas apropriaram-se dos conhecimentos que foram trabalhados no museu, na palestra e durante a trilha pedagógica. Os desenhos mostraram elementos da Fauna e Flora característicos do Cerrado, as árvores continuam apresentando troncos retorcidos, mas agora com a presença de raízes profundas e copas com flores, que imitam os Ipês e folhas caindo. É possível observar ainda a presença de um quantitativo e variedade maior de animais característicos do bioma (Figuras 4 e 5 ). 
Figura 4 - Desenhos produzidos por estudantes do $5^{\mathrm{a}}$ ano A sobre o tema Fauna e Flora do Cerrado, antes e depois da visita ao Parque Zoológico de Goiânia. A codificação A indica a turma e os números indicam o estudante.

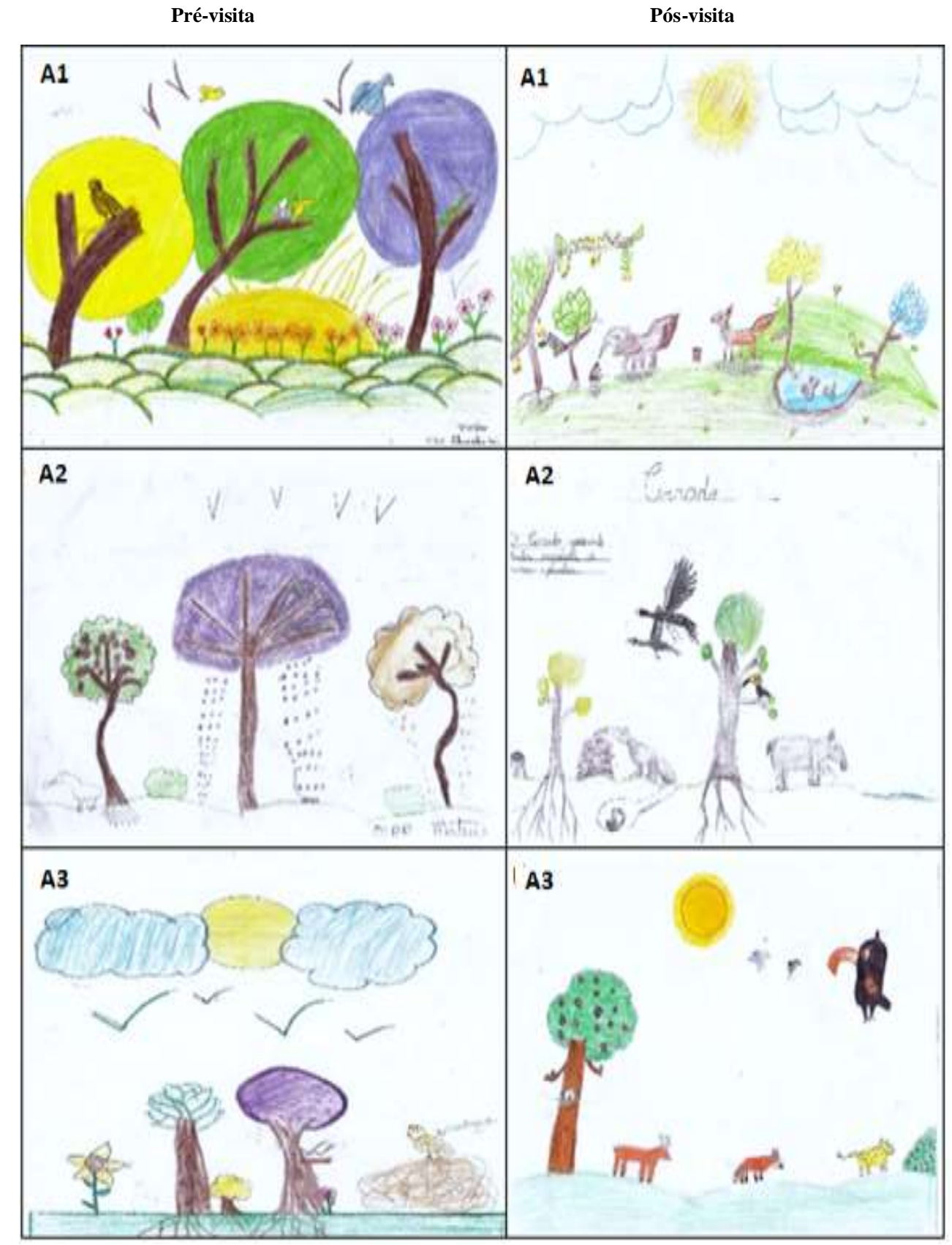

Fonte: Autores. 
Figura 5 - Desenhos produzidos por estudantes do $5^{\mathrm{a}}$ ano B sobre o tema Fauna e Flora do Cerrado, antes e depois da visita ao Parque Zoológico de Goiânia. A codificação B indica a turma e os números indicam o estudante.

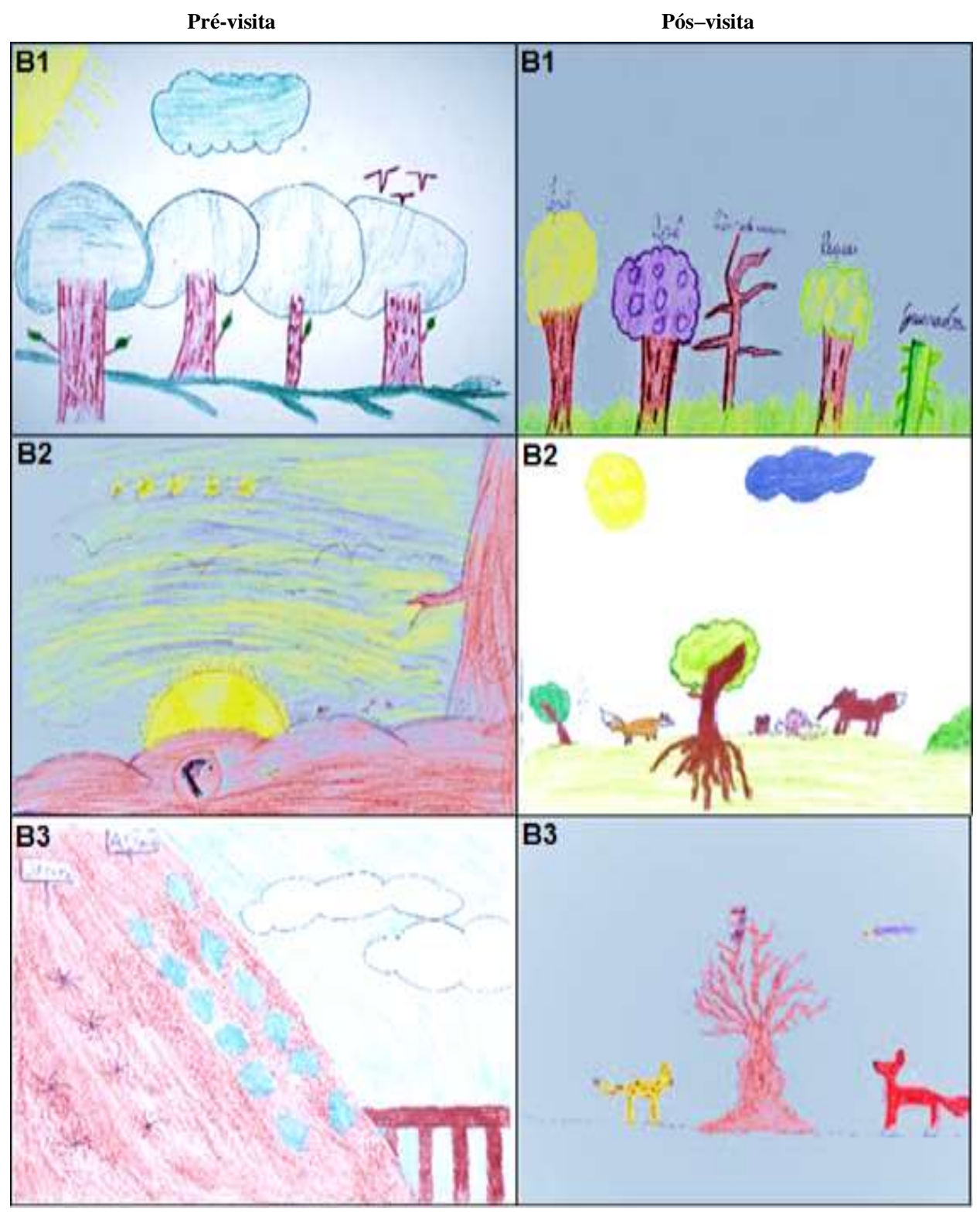

Fonte: Autores (2019).

De acordo com Goldenberg, Yunes e Freitas (2004), os desenhos são importantes ferramentas para mediação do conhecimento. Através deles, a criança é capaz de expressar seu autoconhecimento, experiências e aprendizado. Vygotsky em sua abordagem sócio histórica considera que as expressões gráficas funcionam como símbolo, instrumento psicológico de mediação e interação entre pares e o ambiente social. Segundo o autor, a criança será capaz de expressar o seu conhecimento científico apoiada em experiências cotidianas de acordo com o seu contexto histórico e social e a sua interação com o ambiente (Friedrich, 2012). Nesse sentido, considerando os conhecimentos prévios e a ampliação do conhecimento dos alunos, a Tabela 1 sintetiza os elementos da Fauna e da Flora presentes nos desenhos antes e após a visita ao PZG. 
Tabela 1 - Elementos presentes nos desenhos dos estudantes do $5^{\circ}$ ano A e B ao retratarem a temática Fauna e Flora do Cerrado, antes e depois da visita ao Parque Zoológico de Goiânia. Turma $\mathrm{A}=18$ estudantes e $\mathrm{B}=12$ estudantes. F indica a frequência absoluta considerando o total dos desenhos.

\begin{tabular}{|c|c|c|c|c|}
\hline \multirow[t]{2}{*}{ FAUNA } & \multicolumn{2}{|c|}{ TURMA A } & \multicolumn{2}{|c|}{ TURMA B } \\
\hline & Pré - visita & Pós - visita & Pré - visita & Pós - visita \\
\hline Tamanduá & 2 & 5 & & \\
\hline Lobo-guará & 2 & 8 & & \\
\hline Onça-pintada & & 3 & 2 & 2 \\
\hline Onça-parda & & 1 & & \\
\hline Cutia & & 1 & & \\
\hline Veado-campeiro & & 1 & & \\
\hline Anta & & 3 & & \\
\hline Gato-do-mato & & & & 2 \\
\hline Raposa & & & & 2 \\
\hline Cachorro-do-mato & & & & 2 \\
\hline Tatu & & & & 1 \\
\hline Jacaré & 2 & 2 & & 1 \\
\hline Jabuti & 1 & & & 1 \\
\hline Lagarto & & & & 1 \\
\hline Cobra & 2 & 1 & 2 & 3 \\
\hline Pássaros & & & 1 & 3 \\
\hline Tucano & & 4 & 1 & 2 \\
\hline Pica-pau & & & & 1 \\
\hline Seriema & & 1 & & \\
\hline Papagaio & & 1 & & \\
\hline Coruja & 1 & & & \\
\hline Ema & & 1 & & \\
\hline João-de-barro & 1 & & & \\
\hline Abelhas & 1 & & & \\
\hline Cupinzeiro & 1 & 5 & & 3 \\
\hline \multirow[t]{2}{*}{ FLORA } & \multicolumn{2}{|c|}{ TURMA A } & \multicolumn{2}{|c|}{ TURMA B } \\
\hline & Pré-visita & Pós-visita & Pré-visita & Pós-visita \\
\hline Pequizeiro & 3 & 12 & 1 & 2 \\
\hline Lobeira & 3 & 11 & & \\
\hline Ipês & 1 & 3 & & 4 \\
\hline Pata-de-vaca & & 1 & & 2 \\
\hline Guariroba & & & & 2 \\
\hline Batata & & 1 & & \\
\hline Folhas caindo & 1 & 2 & & \\
\hline Poucas folhas & 2 & 2 & & 4 \\
\hline Sem folhas & & 2 & 1 & 11 \\
\hline Cascas grossas & 2 & 4 & 8 & 9 \\
\hline Troncos e galhos retorcidos & 6 & 11 & 5 & 21 \\
\hline Raízes profundas & 1 & 3 & 5 & 5 \\
\hline Vegetação rasteira & & & 4 & 9 \\
\hline
\end{tabular}

Fonte: Autores (2019).

Ao analisar o conhecimento dos estudantes de acordo com a frequência de respostas do questionário pré-visita (Tabela 2), percebemos que ambas as turmas confirmaram o pouco conhecimento sobre o tema também expresso através dos desenhos 
(Tabela 1). Entretanto, os alunos da turma A apresentam maior conhecimento prévio sobre o tema, como pode ser observado na Tabela 2 .

Tabela 2 - Respostas dos estudantes do $5^{\circ}$ ano do Ensino Fundamental ao questionário sobre o tema Fauna e Flora do Cerrado, aplicado antes da visita ao Parque Zoológico de Goiânia. Turma A = 18 e B = 12 estudantes. Os termos Aberta e Fechada se referem ao tipo de questão, fornecendo alternativas de respostas (Fechada) ou não (Aberta).

\begin{tabular}{|c|c|c|c|}
\hline \multirow[t]{2}{*}{ Questões } & \multirow[t]{2}{*}{ Respostas } & \multicolumn{2}{|c|}{ Frequência } \\
\hline & & A & $\mathrm{B}$ \\
\hline \multirow{7}{*}{$\begin{array}{l}\text { 1. O que é meio ambiente? } \\
\text { (Aberta) }\end{array}$} & Onde os animais, plantas e seres humanos vivem. & 14 & 4 \\
\hline & Onde nós vivemos. & & 3 \\
\hline & É onde vivem espécies animais e de plantas. & & 3 \\
\hline & Onde pisamos. & & 1 \\
\hline & É onde pegamos toda a nossa matéria-prima. & 2 & 1 \\
\hline & Meio ambiente é a natureza. & & 1 \\
\hline & É um lugar limpo e conservado. & 1 & \\
\hline \multirow[t]{5}{*}{$\begin{array}{l}\text { 2.Para que servem os zoológicos? } \\
\text { (Fechada) }\end{array}$} & $\begin{array}{l}\text { Para conservação de animais e como espaço de } \\
\text { aprendizagem e pesquisa. }\end{array}$ & 16 & 4 \\
\hline & Para proteger os animais. & & 2 \\
\hline & Como um local de passeio. & & 2 \\
\hline & Como espaço de aprendizagem. & & 2 \\
\hline & Como local de pesquisa. & & 1 \\
\hline \multirow{5}{*}{$\begin{array}{l}\text { 3.De onde vêm os animais que chegam ao zoológico? } \\
\text { (Aberta) }\end{array}$} & Da natureza. & 7 & 5 \\
\hline & Do Cerrado. & 6 & 3 \\
\hline & Dos circos. & 4 & \\
\hline & São animais que foram pegos com traficantes. & & 3 \\
\hline & Eles são comprados de outros zoológicos. & 1 & 1 \\
\hline \multirow{8}{*}{$\begin{array}{l}\text { 4. Qual o bioma predominante na região Centro-Oeste? } \\
\text { (Aberta) }\end{array}$} & Cerrado. & 10 & 4 \\
\hline & Pantanal. & 4 & \\
\hline & Caatinga. & 4 & \\
\hline & Não conhecem. & & 4 \\
\hline & Goiânia. & & 1 \\
\hline & Tropical. & & 1 \\
\hline & Animais e Plantas. & & 1 \\
\hline & Calor. & & 1 \\
\hline \multirow{5}{*}{$\begin{array}{l}\text { 5.Cite três características das árvores do Cerrado. } \\
\text { (Aberta) }\end{array}$} & Troncos retorcidos. & 12 & 9 \\
\hline & Raízes profundas. & 2 & \\
\hline & Por algum tempo as árvores ficam sem folhas. & 2 & 1 \\
\hline & Tempo de chuva, árvores verdes, tempo de seca, & 1 & \\
\hline & árvores sem folhas. & 1 & \\
\hline \multirow[t]{21}{*}{ 6. Cite o nome de dois animais do Cerrado. (Aberta) } & Lobo-guará. & 12 & 9 \\
\hline & Arara-Brasil. & & 8 \\
\hline & Tamanduá -bandeira. & 3 & 4 \\
\hline & Macaco-prego. & 2 & 3 \\
\hline & Anta. & 2 & 2 \\
\hline & Veado-campeiro. & 2 & 2 \\
\hline & Onça pintada. & 1 & 2 \\
\hline & Arara-azul. & 1 & 2 \\
\hline & Jararaca. & 1 & 2 \\
\hline & Jaguatirica. & 1 & \\
\hline & Tatu. & 1 & \\
\hline & Ema. & 1 & \\
\hline & Canguru. & 1 & \\
\hline & Coelho. & 1 & \\
\hline & Girafa. & & 1 \\
\hline & Cobra. & & 1 \\
\hline & Beija-Flor. & & 1 \\
\hline & Leão. & 1 & \\
\hline & Urubu. & & 1 \\
\hline & Seriema. & & 1 \\
\hline & Cachorro-do-Mato. & & 1 \\
\hline
\end{tabular}




\begin{tabular}{|c|c|c|c|}
\hline \multirow[t]{16}{*}{ 7.Cite duas espécies de plantas do Cerrado. (Aberta) } & Ipê. & 8 & 7 \\
\hline & Pequi. & 8 & 4 \\
\hline & Lobeira. & 3 & 1 \\
\hline & Não conheço. & & 3 \\
\hline & Cenoura. & 2 & 2 \\
\hline & Jacarandá. & 1 & 1 \\
\hline & Pata-de-vaca. & 1 & 1 \\
\hline & Cajuzinho. & 1 & 1 \\
\hline & Laranjeira. & 1 & 1 \\
\hline & Batata. & 1 & \\
\hline & Tomate. & 1 & \\
\hline & Pinheiro. & 1 & \\
\hline & Guariroba. & 1 & \\
\hline & Buriti. & 1 & 1 \\
\hline & Pau-terra. & 1 & 1 \\
\hline & Plantas e árvores. & & 1 \\
\hline \multirow[t]{8}{*}{ 8.Por que é importante preservarmos o Cerrado? (Aberta) } & Para deixar o ar mais puro. & 6 & 5 \\
\hline & Preservar espécies de plantas e animais. & 3 & 2 \\
\hline & Para deixar animais, plantas e nós mesmos vivos. & 4 & 1 \\
\hline & Preservar a natureza. & 2 & 1 \\
\hline & Para a vida continuar existindo. & 2 & 1 \\
\hline & Para preservar árvores e animais. & & 1 \\
\hline & Para preservar as plantas. & 1 & 1 \\
\hline & A importância é muito grande. & 1 & \\
\hline \multirow{9}{*}{$\begin{array}{l}\text { 9. O que você acredita que pode aprender com a visita ao } \\
\text { Parque Zoológico? (Aberta) }\end{array}$} & Como vivem os animais. & 9 & 3 \\
\hline & Sobre animais e plantas. & 8 & 4 \\
\hline & Sobre alimentação. & 7 & 3 \\
\hline & Comportamento dos animais. & 5 & 1 \\
\hline & Nomes científicos dos animais. & 3 & \\
\hline & Animais diferentes. & 2 & 1 \\
\hline & Habitat dos animais. & 2 & 4 \\
\hline & Rotina dos animais. & 2 & 2 \\
\hline & Características dos animais. & 1 & \\
\hline \multirow{8}{*}{$\begin{array}{l}\text { 10. Você acha importante a existência dos Zoológicos? } \\
\text { Por quê? (Aberta) }\end{array}$} & Sim. Podemos aprender sobre os animais. & 10 & 3 \\
\hline & Sim. Os animais estão protegidos & 5 & 1 \\
\hline & zoológicos. & 3 & 2 \\
\hline & Sim. Aprender sobre as plantas. & & 1 \\
\hline & Sim. Para pesquisa científica. & & 2 \\
\hline & Sim. Pois, o zoológico é um lugar para estudo. & & 2 \\
\hline & Sim. Para aprender a respeitar os animais. & & 1 \\
\hline & Sim. Para apreciar os animais. & & 1 \\
\hline
\end{tabular}

Fonte: Autores (2019).

Ao analisar o questionário pós-visita, constatou-se, através da qualidade e da frequência das respostas, que em ambas as turmas houve aproveitamento da atividade de visitação ao PZG, como podemos verificar na tabela 3 e comentários logo abaixo. 
Tabela 3 - Respostas dos estudantes do $5^{\circ}$ ano do Ensino Fundamental ao questionário sobre o tema Fauna e Flora do Cerrado, aplicado depois da visita ao Parque Zoológico de Goiânia. Turma A = 18 e B = 12 estudantes. Os termos Aberta e Fechada se referem ao tipo de questão, fornecendo alternativas de respostas (Fechadas) ou não (Abertas).

\begin{tabular}{|c|c|c|c|}
\hline \multirow[t]{2}{*}{ Perguntas } & \multirow[t]{2}{*}{ Respostas encontradas } & \multicolumn{2}{|c|}{ Frequência } \\
\hline & & A & B \\
\hline \multirow{12}{*}{$\begin{array}{l}\text { 1.Assinale os assuntos que } \\
\text { foram destaque durante a } \\
\text { trilha. (Fechada) }\end{array}$} & Comportamento dos animais. & 12 & 9 \\
\hline & Animais em extinção. & 12 & 10 \\
\hline & Árvores do Cerrado. & 8 & 5 \\
\hline & Habitat dos animais. & 10 & 11 \\
\hline & Morfologia dos animais. & 2 & 1 \\
\hline & Beleza dos recintos. & 2 & 1 \\
\hline & Alimentação dos animais. & 15 & 11 \\
\hline & Animais do Cerrado. & 12 & 9 \\
\hline & Reprodução dos animais. & 3 & 5 \\
\hline & Leitura das placas. & 11 & 5 \\
\hline & Situação do recinto. & 4 & 1 \\
\hline & Animais de vida livre. & 4 & 1 \\
\hline \multirow[t]{5}{*}{$\begin{array}{l}\text { 2. Por que é importante } \\
\text { preservar o Cerrado? (Aberta) }\end{array}$} & $\begin{array}{l}\text { Preservar plantas e animais que só existem no } \\
\text { Cerrado. }\end{array}$ & 6 & 9 \\
\hline & $\begin{array}{l}\text { Para proteger a vegetação e não ficarmos sem } \\
\text { água. }\end{array}$ & 4 & 1 \\
\hline & Para que o Cerrado não acabe. & 2 & 1 \\
\hline & Para a água não acabar. & 3 & \\
\hline & Para preservação dos animais. & 3 & 1 \\
\hline \multirow{12}{*}{$\begin{array}{l}\text { 3. Assinale os nomes de } \\
\text { animais do Cerrado vistos no } \\
\text { zoológico. } \\
\text { (Fechada) }\end{array}$} & Anta. & 16 & 10 \\
\hline & Tigre. & 4 & 5 \\
\hline & Onça-Pintada. & 15 & 8 \\
\hline & Tucano. & 4 & 8 \\
\hline & Suçuarana. & 7 & 7 \\
\hline & Urso-Pardo. & 3 & 4 \\
\hline & Pantera. & 3 & 5 \\
\hline & Ema. & 10 & 6 \\
\hline & Jacaré-de-papo-amarelo. & 10 & 7 \\
\hline & Lobo-Guará. & 17 & 12 \\
\hline & Arara-Canindé. & 12 & 6 \\
\hline & Avestruz. & 4 & 7 \\
\hline \multirow{7}{*}{$\begin{array}{l}\text { 4. Qual o bioma predominante } \\
\text { na região Centro-Oeste? } \\
\text { (Aberta) }\end{array}$} & Cerrado, & 11 & 7 \\
\hline & Caatinga. & 2 & \\
\hline & Pantanal. & 5 & \\
\hline & Tropical. & & 1 \\
\hline & Cerrado amazônico. & & 1 \\
\hline & $\begin{array}{l}\text { Seco, chove bem raramente, com árvores grandes. } \\
\text { Galhos secos, sem folhas. }\end{array}$ & & 1 \\
\hline & & 8 & 2 \\
\hline
\end{tabular}




\begin{tabular}{|c|c|c|c|}
\hline \multirow{8}{*}{$\begin{array}{l}\text { 5. Cite três características das } \\
\text { árvores do Cerrado. (Aberta) }\end{array}$} & Troncos retorcidos. & 13 & 7 \\
\hline & Cascas grossas. & 5 & 1 \\
\hline & Raízes profundas. & 7 & 1 \\
\hline & Resistem ao fogo. & 3 & \\
\hline & Folhas secas. & 2 & \\
\hline & Raízes tortas. & & 1 \\
\hline & Troncos tortos. & & 1 \\
\hline & Galhos tortos. & & 3 \\
\hline \multirow{6}{*}{ 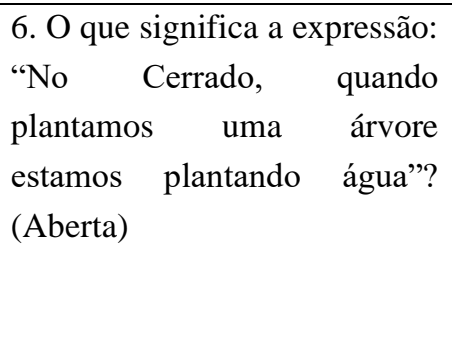 } & As raízes das árvores levam água para o subsolo. & 6 & 3 \\
\hline & $\begin{array}{l}\text { A vegetação ajuda a manter a água em baixo do } \\
\text { solo. }\end{array}$ & 6 & 2 \\
\hline & As raízes levam água para o lençol freático. & 3 & 2 \\
\hline & As árvores protegem as nascentes dos rios. & 3 & \\
\hline & Significa que o cerrado está sendo preservado. & & 1 \\
\hline & Porque as raízes são profundas. & 5 & 4 \\
\hline \multirow{9}{*}{$\begin{array}{l}\text { 7. Assinale as espécies de } \\
\text { plantas que são nativas do } \\
\text { Cerrado. (Fechada) }\end{array}$} & Pequi. & 17 & 9 \\
\hline & Ipê. & 16 & 10 \\
\hline & Jatobá. & 9 & 4 \\
\hline & Guariroba. & 4 & 4 \\
\hline & Pinheiro. & 4 & 3 \\
\hline & Palmeira-Imperial. & 4 & 2 \\
\hline & Eucalipto. & 5 & 5 \\
\hline & Pata-de-vaca. & 4 & 7 \\
\hline & Pau-de-leite. & 6 & 3 \\
\hline \multirow{16}{*}{$\begin{array}{l}\text { 8. Na sua opinião, o zoológico } \\
\text { de Goiânia está localizado } \\
\text { numa região apropriada para o } \\
\text { bem-estar dos animais? Por } \\
\text { quê? (Aberta) }\end{array}$} & Sim. Fica na zona urbana, tem muitas plantas e os & 1 & 1 \\
\hline & ambientes são adequados para cada animal. & 16 & \\
\hline & Não. Tem muita movimentação em volta e & 8 & \\
\hline & barulho. & 4 & 3 \\
\hline & Não. Por causa do barulho dos carros. & 1 & \\
\hline & $\begin{array}{l}\text { Não. A audição dos animais é bem sensível ao } \\
\text { barulho. }\end{array}$ & 1 & 3 \\
\hline & Não. O zoológico não é o ambiente natural deles. & & 1 \\
\hline & Não. O barulho deixa os animais estressados. & 1 & 3 \\
\hline & Sim. Porque tem muitos animais correndo risco de & & 1 \\
\hline & extinção e são preservados no Zoológico. & & 1 \\
\hline & Sim. Porque são bem tratados. & & 1 \\
\hline & Sim. Porque são bem seguros. & & 1 \\
\hline & $\begin{array}{l}\text { Sim. Porque mesmo que alguns animais não sejam } \\
\text { nativos dali, são bem cuidados por especialistas. }\end{array}$ & & 1 \\
\hline & Sim. Porque podemos aprender com eles e assim & & 1 \\
\hline & sobreviverão. & & 1 \\
\hline & Sim. Porque o local é úmido e não calorento. & & 1 \\
\hline \multirow{6}{*}{$\begin{array}{l}\text { 9. O que você aprendeu com a } \\
\text { visita ao zoológico? (Aberta) }\end{array}$} & Os nomes científicos dos animais. & 4 & \\
\hline & $\begin{array}{l}\text { Que os filhotes de alguns animais ficam separados } \\
\text { dos seus pais. }\end{array}$ & 2 & \\
\hline & Sobre animais e plantas do Cerrado. & 9 & 4 \\
\hline & A respeito de animais taxidermizados. & 9 & \\
\hline & Alguns animais do Zoológico têm vida livre. & 8 & \\
\hline & Sobre o habitat dos animais. & 12 & 5 \\
\hline
\end{tabular}


Que alguns animais do zoológico eram de circos

8 ou foram resgatados.

Como é importante plantar árvores para alimentar

o subsolo de água.

Respeitar as plantas e animais. $\quad 6 \quad 2$

Que devemos cuidar respeitar e proteger as plantas $\quad 10 \quad 1$ e os animais.

Mamíferos, répteis, aves, insetos e plantas. $\quad 9$

Aprendemos como plantar uma árvore. $\quad 17$

Alimentação.

Como eles se defendem.

O bioma dos animais.

Preservação do cerrado e outros lugares.

10. Cite dois exemplos de cada classe

de animais (mamíferos, aves e répteis)

vistos no zoológico. (Aberta)

\begin{tabular}{|c|c|c|c|}
\hline Mamíferos & & & \\
\hline & Anta. & 12 & 4 \\
\hline & Leão. & 1 & 1 \\
\hline & Macaco-prego. & 1 & \\
\hline & Onça-pintada. & 13 & 4 \\
\hline & Lobo-guará. & 14 & 4 \\
\hline & Tigre. & 3 & 6 \\
\hline & Canguru. & & 1 \\
\hline & Urso-pardo. & 1 & 1 \\
\hline & Cachorro-do-mato. & 1 & \\
\hline & Jaguatirica. & 1 & \\
\hline & Pantera. & 2 & \\
\hline & Hipopótamo. & 1 & \\
\hline \multicolumn{4}{|l|}{ Aves } \\
\hline & Arara-Canindé. & 12 & 3 \\
\hline & Avestruz. & 1 & 1 \\
\hline & Tuiuiú. & 3 & \\
\hline & Pavão. & 4 & \\
\hline & Cisne-negro. & 3 & \\
\hline & Grou. & 6 & \\
\hline & Tucano. & 5 & 7 \\
\hline & Ema. & 4 & 1 \\
\hline & Seriema. & 3 & \\
\hline & Arara azul. & 1 & 3 \\
\hline & Coruja. & 1 & \\
\hline & Papagaio. & 2 & 1 \\
\hline & Arara. & & 1 \\
\hline \multicolumn{4}{|l|}{ Répteis } \\
\hline & Cobra-preta. & & 2 \\
\hline & Camaleão. & & 1 \\
\hline & Cobra. & 2 & 1 \\
\hline & Sucuri. & 1 & 3 \\
\hline
\end{tabular}




\begin{tabular}{lll}
\hline & Píton. & 1 \\
& Jabuti. & 1 \\
\hline
\end{tabular}

Fonte: Autores (2019).

Os questionários pré e pós-visita apresentam três questões abertas em comum e através delas foi possível constatar que os estudantes demonstraram ter ampliado o conhecimento após a visita ao PZG. Ao comparar as respostas das questões: "Qual o bioma predominante da região Centro-Oeste”, observamos que, tanto na turma A quanto B, houve aumento no número de alunos que responderam "Cerrado". Na questão que pede para que os alunos citem três caraterísticas do Cerrado, verifica-se que, em ambas as turmas, a característica "troncos retorcidos" aparece nos questionários pré-visita, entretanto, depois da visita aparecem com maior frequência, seguida de outras duas características (cascas grossas e raízes profundas, resistentes ao fogo) que não apareciam antes. Quando questionados sobre por que é importante preservarmos o Cerrado, foi expressivo o número de alunosque relacionaram isso à preservação da Fauna e da Flora, dos recursos hídricos e da qualidade do ar.

Ao analisarmos as respostas das outras questões, tanto abertas quanto fechadas, do questionário pós-visita, percebemos que houve um bom aproveitamento das atividades, principalmente no que diz respeito aos assuntos abordados durante a palestra e a trilha sobre: identificação de espécies da Fauna e da Flora do Cerrado, comportamento dos animais, alimentação dos animais, animais de vida livre no PZG, nomes científicos, animais taxidermizados vistos no museu, origem dos animais que chegam ao zoológico, características das espécies de árvores do Cerrado. Além disso, os alunos conseguiram compreender a importância da preservação da vegetação para proteger as nascentes, através da interpretação da frase "No Cerrado, quando plantamos árvore, plantamos água”, entenderam que o PZG está localizado em lugar inadequado, o que prejudica a saúde dos animais e citaram exemplos de espécies de mamíferos, aves e répteis vistos no Zoológico.

Por fim, a exposição dos desenhos e o relato das experiências vivenciadas no zoológico para a comunidade escolar demonstraram o quanto a visita ao PZG foi importante para o conhecimento dos alunos. Eles demonstraram entusiasmo com o fato de compartilharem seus desenhos e o conhecimento adquirido. A experiência do plantio da muda de Ipê, como proposta de contribuir para a proteção das nascentes do Parque, a função dos zoológicos de preservação e conservação e a importância de preservar o Cerrado foi bastante enfatizada pelos alunos aos colegas durante a exposição.

Ao questionar as professoras sobre as contribuições do PZG para o processo de alfabetização científica dos alunos, ambas consideraram que a ida ao zoológico foi uma experiência de campo acompanhada de informações que contribuíram para ampliar o conhecimento científico dos alunos. A professora A ressaltou que o plantio do Ipê foi uma das experiências mais relevantes para a turma.

Quanto à mediação, ambas comentaram que a equipe ambiental superou as expectativas, houve integração entre equipe escolar e o PZG através de ofício e informações trocadas por $e$-mail a respeito do quantitativo de alunos, bem como sobre o tema de interesse da palestra e a trilha desejada. A professora A ressaltou que os alunos sentiram-se acolhidos pela equipe de educadores.

Sobre o processo de internalização do conhecimento, tanto a professora A, quanto a professora B esclareceram que a palestra a respeito da preservação da Fauna e da Flora do Cerrado, a trilha pelos recintos e o plantio de mudas foram significativos na promoção desse processo pelos alunos.

A respeito do $\mathrm{PZG}$ atender às necessidades de alunos com deficiência, ambas concordam que, embora o parque atenda pessoas com dificuldades de locomoção, o espaço deixa a desejar nesse quesito, pois não há piso tátil para portadores de deficiência visual. Na opinião das professoras, as educadoras ambientais utilizaram linguagem adequada à faixa etária dos alunos.

Questionando as professoras sobre a relevância dos temas abordados durante a visita pelos educadores ambientais, 
ambas enfatizaram o estranhamento dos animais nos recintos, a importância da preservação da Fauna e da Flora, a necessidade de conscientizar as pessoas sobre educação ambiental. Além disso, segundo as professoras, os temas oportunizaram a ampliação dos conhecimentos sobre o bioma do Cerrado, alimentação, hábitos dos diversos animais, cadeia alimentar, animais em extinção, adaptação dos recintos e classificação dos animais.

Quanto à percepção das educadoras ambientais, ambas consideraram que a interação entre alunos, professores e educadores ambientais foi constante. A palestra foi uma exposição dialogada em que os alunos tiveram liberdade para questionar e colocar seus conhecimentos. Embora os conhecimentos prévios dos alunos sobre animais e características do Cerrado tenham se mostrado rasos, as educadoras ambientais afirmam que os alunos demonstraram oralmente algum conhecimento prévio sobre o tema. Para elas, o que mais chamou atenção dos alunos durante a palestra foi o resgate de animais, comportamento e curiosidades de algumas espécies e, durante a trilha, o serpentário.

Questionadas se consideravam que os alunos compreenderam a função do PZG, ambas responderam que sim e uma delas ressaltou que os alunos fizeram perguntas pertinentes sobre o assunto, cujas mais frequentes, em ambas as turmas, foram sobre a fauna do Cerrado, flora do Cerrado, hábitos alimentares, comportamento dos animais, leitura de placas e caraterísticas morfológicas dos animais. A turma B questionou mais sobre flora do Cerrado, cadeia alimentar, hábitos alimentares, animais em extinção e animais de vida livre no zoológico. De acordo com a análise dos dados das percepões dos estudantes, das professoras e das educadores ambientais, podemos concluir que após a experiência no PZG, houve ampliação significativa do conhecimento científico dos alunos. Isso demonstra que o PZG constitui-se um espaço não formal com grandes possibilidades para desenvolver a aprendizagem, contribuindo com o processo de alfabetização científica dos que o visitam. Carvalho et al (2018), através de trabalho semelhante realizado no Bosque da Ciência em Manaus, esclarecem e concordam que a riqueza dos espaços não formais e a interação com estes, contribuem de forma lúdica para o processo de alfabetização científica dos alunos.

\section{Considerações Finais}

A grande maioria dos alunos participantes da pesquisa não conheciam o PZG e esta foi, sem dúvida, uma grande oportunidade para que estes alunos conhecessem esse ambiente. Isso demonstra o quanto é importante o papel da escola de planejar e oportunizar atividades e situações de aprendizagens nesses espaços. Entendemos que os espaços não formais permitem e propiciam situações de aprendizagens interativas e significativas, além de funcionarem como parceiros do processo de construção do conhecimeno dos alunos.

Durante a visitação ao PZG, os alunos desenvolveram várias habilidades e, neste contexto, podemos citar o fato de realizarem observações, fazerem leituras das placas, coletarem informações através de questionamentos e, a partir da interação com os professores e educadores ambientais e o ambiente, apropriaram-se de novos conhecimentos científicos.

Diante dos resultados apresentados, podemos afirmar que o PZG é um espaço não formal de educação capaz de contribuir para o processo de alfabetização científica dos visitantes, de auxiliar a escola a despertar o interesse dos alunos de forma lúdica, descontraída e agradável, através de atividades planejadas e em consonância com o interesse das escolas.

Inicialmente nosso propósito era incluir um quantitativo maior de turmas, infelizmente isso não foi possível devido à pandemia de COVID-19. Sugerimos que trabalhos semelhantes sejam realizados com um número maior de turmas, incluindo outros níveis de ensino, com o propósito de investigar minuciosamente os indicadores de alfabetzação científica desses espaços. 


\section{Referências}

Araújo, I. dos S. C. (2015) Alfabetização científica: concepções de educadores. Revista Contexto \& amp; Educação $29(4), 4$-26.

Ausubel, D., Novak, J., Hanesiah, H. (1980). Psicologia Educacional. (2a ed.). Interamericana. 326 p.

Bardin, L. (1997). Análise de conteúdo. Edições 70.

Cachapuz, A., Praia, J. \& Jorge, M. (2004). Da educação em ciência às orientações para o ensino das ciências: um repensar epistemológico. Ciência \& Educação, 10(3), 363-381.

Carvalho, F. B., Beltrão, g. G. B. (2018). Possibilidades de alfabetização científica no Bosque da Ciência, Manaus, AM, Brasil. Revista da Rede Amazônica de Educação Ciência e Matemática. 6(2), 34-35. http://periodicoscientificos.ufmt.br/ojs/index.php/reamec.

Chassot, A. (2003). Alfabetização científica: uma possibilidade para inclusão social. Revista Brasileira de Educação. 22, 89 -100. http://www.scielo.br/scielo.php

Fernandes, J. A. B. (2007). Você vê essa adaptação? A aula de campo em ciências entre o retórico e o empírico. (Tese de doutorado) Faculdade de Educação da Universidade de São Paulo. FAESP. Brasil.

Friedrich, J. (2012). O aporte específico da escola: A distinção entre conceitos científicos e conceitos cotidianos. In Vygotsky, Lev. Mediação, aprendizagem e desenvolvimento - uma leitura filosófica e epistemológica. Mercado de Letras. cap. 5, pp. 99-117.

Goldenberg, L. G., Yunse, M. A. M. \& Freitas, J. V. (2005). O desenho infantil na ótica da ecologia do desenvolvimento humano. Psicologia em estudo. 10(1), 97-106. http://www.scielo.br.

Jacobucci, F. C. (2008). Contribuições dos espaços não formais de educação para a formação da cultura científica. Revista em Exensão, 7(1), 5. http;//beer.uf.br.

Laugksch, R. C. Scientific Literacy: A Conceptual overview. (2000). Science Education. 84(1), 71-94. www.kcvs.ca/martin/edec/litercy/laugkch.

Lorenzetti, L. \& Delizoicov, D. (2001) Alfabetização científica no contexto das séries iniciais. Ensaio Pesquisa em Educação em Ciência. 3(1), 1-17. Recuperado de www.kcvs.ca/martin/edcl/literacy/laugkch.

Molon, S. I. (2015). Subjetividade e constituição do sujeito em Vygotsky. (5a ed).Vozes.

Moura, A. B. F \& Lima, M. G. S. B. A. (2014). reinvenção da roda: roda de conversa um instrumento metodológico possível. Revista Interface, 5(15), 24-35. https://periodicosonline.uems.br.

Oliveira, M. K. de. ( 2019) Quinto capítulo: O Problema da Afetividade em Vygotsky. In Taille, Y. De La, Oliveira, M. K. \& Dantas, H. Piaget, Vygotsky e Wallon: Teorias Psicopedagógicas em Discussão. (28a. Ed). São Paulo: Summus. 175 p. cap. 5, p.

Queiroz, [R]., Teixeira, H., Veloso, A., Terán, A., \& Queiroz, [A]. (2017). A caracterização dos espaços não formais de educação científica para o ensino de ciências. Revista Areté| Revista Amazônica De Ensino De Ciências, 4 (7), 12-23. http://periodicos.uea.edu.br/index.php/arete/article/view/20.

Rego,T. C. \& Vygotsky, L. S. (2014.) Uma perspectiva histórico-cultural da educação. In Interação entre aprendizado e desenvolvimento: A zona de desenvolvimento proximal. (25a ed). Vozes. 70-75 p.

Rocha, C. \& Malheiro, J. M. (2021) Experimentação investigativa e interdisciplinaridade como promotora da escrita e desenho no ensino de ciências. Revista de Ensino de Ciências e Matemática, 11(6), 409-426. http://revistapos.cruzeirodosul.edu.br.

Sasseron, L. H. \& Carvalho, A. M. (2008). Almejando a alfabetização científica no Ensino fundamental: a proposição e procura de indicadores do processo. Investigações em Ensino de Ciências. 13, 333-352.

Sasseron, L. H. \& Carvalho, A.M. P. (2011). Alfabetização científica: uma revisão bibliográfica. Investigações no ensino de Ciências. 16(1), 59-77. http://www.seer.ufu.br/index.php/revextensao/article/view/20390.https://www.if.ufrgs.br/cref/ojs/index.php/ienci/article/view/246.

Souza, J., \& Campos, C. ( 2020). Uma aula de campo no parque mochuara: atividades investigativas para a Alfabetização Científica. Revista de Ensino de Ciências e Matemática, 11(6), 761-778. 2020. http://revistapos.cruzeirodosul.edu.br.

Vygotsky, L.S. (1991). A formação social da mente. (4a ed.), Martins Fontes, 168 p.

Vigotsky. L. S. (2003). Pensamento e Linguagem. (2a ed.) Martins Fontes.

Vieira, V. Bianconi, M. L., \& Dias, M. (2005). Espaços não-formais de ensino e o currículo de ciências. Ciência e Cultura, 57(4), 21-23. http://cienciaecultura.bvs.br/scielo.php?script=sci_arttext\&pid=S0009-67252005000400014\&lng=en\&tlng=pt. 